\title{
Jean-Jacques Rousseau, Il contratto sociale
}

\section{Paola Sosso}

\section{(2) OpenEdition}

\section{Journals}

\section{Edizione digitale}

URL: https://journals.openedition.org/studifrancesi/37778

DOI: 10.4000/studifrancesi.37778

ISSN: 2421-5856

\section{Editore}

Rosenberg \& Sellier

\section{Edizione cartacea}

Data di pubblicazione: 15 décembre 2004

Paginazione: 616

ISSN: 0039-2944

\section{Notizia bibliografica digitale}

Paola Sosso, «Jean-Jacques Rousseau, I/ contratto sociale», Studi Francesi [Online], 144 (XLVIII | III) | 2004, online dal 30 novembre 2015, consultato il 08 mai 2021. URL: http://journals.openedition.org/ studifrancesi/37778; DOI: https://doi.org/10.4000/studifrancesi.37778

\section{Questo documento è stato generato automaticamente il 8 mai 2021.}

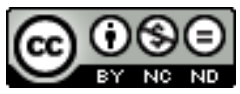

Studi Francesi è distribuita con Licenza Creative Commons Attribuzione - Non commerciale - Non opere derivate 4.0 Internazionale. 


\title{
Jean-Jacques Rousseau, Il contratto sociale
}

\author{
Paola Sosso
}

\section{NOTIZIA}

JEAN-JACQUES ROUSSEAU, Il contratto sociale, introduzione di Alberto BURGIO, note di Andrea MARCHILI, Milano, Feltrinelli, 2003, pp. 252.

1 Questa edizione, che riprende la traduzione di Jole Bertolazzi del 1970 (in Scritti politici, a cura di Paolo Alatri, Torino, Utet) è introdotta da un saggio di Alberto Burgio che ha il pregio di mettere in luce alcuni degli aspetti fondamentali del pensiero politico di JeanJacques, troppo spesso mal interpretato e mal compreso. In una prima parte dell'introduzione, dopo una rapida ricostruzione del contesto storico e culturale del Contrat social, il curatore ripercorre le fonti dell'opera del ginevrino e segue le tappe della genesi del testo e la sua storia editoriale. Nella sezione successiva, Alberto Burgio mostra come la modernità, dato irreversibile per Rousseau, necessiti di essere difesa da se stessa: allorquando la condizione sociale sostituisce l'ottica naturale, l'egoismo dei singoli rischia di condurre il corpo sociale alla dissoluzione, perché non sempre il popolo è in grado di vedere e volere il proprio bene. In questo senso, la volontà generale è definita da Rousseau nei termini di un concerto regolativo di sapore Kantiano: è il volere di un'assemblea che si orienta effettivamente verso il bene dei cittadini. Il popolo ha tuttavia bisogno di una guida, prima fra tutte il legislatore, mentre le decisioni dell'assemblea sovrana si devono tenere nel solco di saldi principi etici: quest'ultimo elemento è coerente con il principio di costituzionalità elaborato dal costituzionalismo post-positivistico e contribuisce a rendere moderna un'opera che preconizza, senza lasciarsi andare a facili illusioni, un difficile equilibrio tra sistema giuridico e principi etici. Chiude il saggio un rapido sunto relativo alla storia della fortuna e della critica. Precedono ancora il testo una rapida presentazione della vita e delle opere di Jean-Jacques e una bibliografia essenziale. L'apparato di note ha lo scopo di facilitare la lettura del testo, illustrando la struttura formale dell'opera, i raccordi 
tematici interni, le fonti utilizzate da Rousseau e il contesto in cui si collocano, nonché mettere in rilievo le indicazioni di carattere storico e biografico. Il volume si conclude con un'appendice che include il secondo capitolo del primo libro del cosiddetto Manuscrit de Genève, capitolo soppresso nella versione definitiva, dal titolo La società generale del genere umano. 